\title{
Pattern and risk factors for childhood injuries in Dar es Salaam, Tanzania
}

\author{
Robert Moshiro $^{1,2}$, Francis F Furia ${ }^{1,2}$, Augustine Massawe ${ }^{1,2}$, Elia John Mmbaga ${ }^{3}$
}

1. Department of Paediatrics, Muhimbili National Hospital, Dar es Salaam, Tanzania.

2. Department of Paediatrics and Child Health, School of Medicine, Muhimbili University of Health and Allied Sciences, Dar es Salaam, Tanzania.

3. Department of Epidemiology and Biostatistics, School of Public Health and Social Sciences, Muhimbili University of Health and Allied Sciences, Dar es Salaam, Tanzania.

\section{Authors emails:}

RM: moshiror@gmail.com; AM: draugustine.massawe@gmail.com; EJM: eliajelia@yahoo.co.uk

\begin{abstract}
Background: Injuries contribute to morbidity and mortality in children. This study was carried out to describe the pattern of childhood injuries and associated risk factors in Dar es Salaam, Tanzania.

Methods: This case control study was conducted in six selected health facilities in Dar es Salaam, Tanzania. Data were collected using a structured questionnaire. Cases and controls were children below 18 years who had suffered injuries and those without injury associated condition respectively.

Results: A total of 492 cases and 492 controls were included in the study, falls (32\%), burns (26\%), Road Traffic Injuries $(14 \%)$ and cuts $(10 \%)$ were the major types of injuries identified. Younger parents/guardians Adjusted odds ratio (AOR)= 1.4; 95\% CI: $1.4-3.6\}$, more than six people in the same house (AOR=1.8; 95\% CI: 1.3-2.6), more than three children in the house $\{\mathrm{AOR}=1.4 ; 95 \% \mathrm{CI}(1.0-2.0)\}$, absence of parent/guardian at time of injury occurrence $(\mathrm{AOR}=1.6 ; 95 \% \mathrm{CI}$ : 1.1-2.3), middle socio-economic (AOR=1.6; 95\%CI: 1.1-2.4) and low socio-economic status (AOR=1.5; 95\% CI: 1.0-2.1) were independent risk factors for childhood injury.

Conclusion: Falls, burns and road traffic injuries were the main injury types in this study. Inadequate supervision, overcrowding, lower socio-economic status and low maternal age were significant risk factors for childhood injuries.

Keywords: Childhood injuries, risk factors, Dar es Salaam, Tanzania.

DOI: https://dx.doi.org/10.4314/ahs.v21i2.42

Cite as: Moshiro R, Furia FF, Massawe A, Mmbaga EJ. Pattern and risk factors for childhood injuries in Dar es Salaam, Tanzania. Afri Health Sci. 2021;21(2). 817-825. https://dx.doi.org/10.4314/abs.v21i2.42
\end{abstract}

\section{Background}

Injuries are damages to human body following exposure to mechanical, chemical, thermal or radiation energy. They contribute to significantly high morbidity and mortality and it is estimated that about 35 million deaths globally were attributed to unintentional injuries between 2007 and $2017 .{ }^{1}$ Children are among the most

\section{Corresponding author: \\ Francis F Furia, \\ Department of Paediatrics, Muhimbili \\ National Hospital, Dar es Salaam, Tanzania; \\ Department of Paediatrics and Child Health, \\ School of Medicine, Muhimbili University of \\ Health and Allied Sciences, Dar es Salaam, Tanzania. \\ Email: fredrick.francis78@gmail.com}

affected population with injuries and in 2015 about 177,000 children were estimated to have died of injuries in Africa. ${ }^{2-4}$

Unintentional childhood injuries include falls, road traffic injury and burns contribute to high mortality and morbidity with Africa, predominantly male and younger children are more affected. ${ }^{5,6}$ Intentional injuries also contribute to severe morbidity and long-term disability in children. ${ }^{7}$

Several factors contribute to high burden of childhood injuries in lower and income countries; these include behavior of children, employment of parents, social supports, rapid urbanization and motorization with increased use of motorcycles. ${ }^{8-11}$ Understanding the pat- 
tern and factors contributing to injuries is key to designing and implementing preventive measures, therefore this study was aimed at describing the pattern of injuries and contributing factors among children in Dar es Salaam, Tanzania.

\section{Methodology}

\section{Study Design and Setting}

This matched case control study was conducted between August 2011 and March 2012 in six health facilities in Dar es Salaam city which has an estimated population of 5 million inhabitants $40 \%$ of which are children.12 Participants were recruited in three regional hospitals (Mwananyamala, Amana and Temeke) and three health centres (Buguruni, Mbagala and Sinza).

\section{Study population}

Children below 18 years who presented to the facilities were eligible, cases were recruited in the casualty departments while controls were recruited in recruited in the follow up and child health clinics in the same facility. Injury was defined as physical damage to the body resulting from exposure to mechanical, thermal, electrical or chemical energy. Birth injuries were excluded from this study.

\section{Sample Size and Power}

Werneck et al report from a study conducted in Brazil to assess the effect of parity on burn injury was used for calculating sample size (Werneck and Reichenheim 1997).13 Using Fleiss formula, a minimum 265 pairs of cases and control were needed to give a power of $90 \%$ with $95 \%$ confidence interval, using case; control ratio of $1: 1$ and detection odds ratio of 2.14

\section{Data collection}

Two research assistants were placed at each facility. . An attending doctor on duty together with research assistant identified children with injuries and collected data from accompanying parents/guardians using structured questionnaires. Cases were recruited fromthe outpatient casualty department. After identifying the case, age and sex matched control was then identified the same day in the same facility. Controls aged below 5 years were recruited from reproductive and child health follow up clinic, which offers routine immunization and growth monitoring for under-five children. Controls aged 5 years and above were recruited from children who vis- ited outpatient clinic due to other illnesses apart from injury. If a matched control was not found on the same day that case was recruited, recruitment was made on the following day. Recruitment of participants and data collection process was stopped when sample size was achieved.

Information collected included nature of injury as the main variable, other information included demographics; age, sex, marital status, and occupation, level of education, number of children in the family and number of occupants in the household. Source of household energy and/or light and presence of chemicals within reach of children was also inquired.

\section{Data analysis}

Data were entered into Statistical Package for Social Sciences (SPSS) version 15 for analysis. Data were summarized into two-way table and were analyzed using Chi Square test and Student $\mathrm{t}$ test to determine differences between categorical and continuous variables respectively. Logistic regression was used to estimate Odds Ratios (ORs), Adjusted Odds Ratio (AOR) and 95\% confidence intervals to ascertain independent risk factors for injury. Risk factors with a $\mathrm{p}$ value less or equal to 0.2 were selected for multivariate logistic regression model. All statistical tests were two-tailed and significance level set at 5\%.

Socio-economic status was classified into poor, middle and wealthier categories. These scales were generated based on analysis of items such as TV, radio and house characteristics, type of toilet, and types of roofing material. The scale had a Cronbach's alpha of 0.823 as a measure of internal consistency. Logistic regression was used to estimate Odds Ratios (ORs), Adjusted Odds Ratio (AOR) and 95\% confidence intervals to ascertain independent risk factors for injury. Risk factors with a $\mathrm{p}$ value less or equal to 0.2 were selected for multivariate logistic regression model. All statistical tests were twotailed and significance level set at 5\%.

\section{Ethical consideration}

Muhimbili University of Health and Allied Sciences (MUHAS) Institution Review Board granted ethical approval for this study, and permission to conduct this study was granted by involved hospital administrations. Before recruitment informed consent was sought from parents/guardians and assent was obtained from children aged $\geq 10$ years and above.

\section{Results}


Social-demographic characteristics of the study participants

A total of 492 cases and 492 controls were recruited from six selected facilities in the city. The mean age for cases and controls were $55.2 \pm 4.5$ and $54.8 \pm 4.5$ months, respectively. Male children accounted for $58 \%$ of injured children. The age group 1-4 years accounted for $61 \%$ of all injured children. Parents/ guardians of children who presented with injuries (cases) were significantly younger than those of controls. Socio-economic status of parents in the control group was noted to be higher than in the cases, $\mathrm{p}=0.001$ (Table 1).

As described in Table 2, children with injuries were

Table 1: Comparisons of socio-demographic characteristics of parents/guardian among the cases and controls

\begin{tabular}{|c|c|c|c|c|}
\hline Variable & Total & $\begin{array}{l}\text { Cases } \\
\mathbf{n}(\%)\end{array}$ & $\begin{array}{l}\text { Control } \\
\text { n(\%) } \\
\end{array}$ & $P$ value \\
\hline $\begin{array}{l}\text { Maternal age } \\
\text { (yrs) }\end{array}$ & & & & \\
\hline $15-24$ & 237 & $119(24.2)$ & $118(24.0)$ & 0.005 \\
\hline $25-34$ & 505 & $273(55.5)$ & $232(47.2)$ & \\
\hline $35+$ & 242 & $100(20.3)$ & $142(28.9)$ & \\
\hline Total & 984 & 492 & 492 & \\
\hline \multicolumn{5}{|l|}{ Education } \\
\hline No education & 83 & $38(7.7)$ & $45(9.1)$ & 0.5 \\
\hline Primary & 567 & $291(59.1)$ & $276(56.1)$ & \\
\hline Secondary+ & 334 & $163(33.2)$ & $171(34.8)$ & \\
\hline Total & 984 & 492 & 492 & \\
\hline \multicolumn{5}{|l|}{ Marital status } \\
\hline Single & 163 & 73 (14.9) & $90(18.3)$ & 0.20 \\
\hline Married & 713 & $369(75)$ & 344 (69.9) & \\
\hline Separated & 108 & $50(10.2)$ & $58(11.8)$ & \\
\hline Total & 984 & 492 & 492 & \\
\hline \multicolumn{5}{|l|}{ Occupation } \\
\hline Peasant & 45 & $30(6.1)$ & $15(3.0)$ & 0.06 \\
\hline Employed & 232 & $121(24.6)$ & $111(22.6)$ & \\
\hline Petty trader & 390 & $186(37.8)$ & $204(41.5)$ & \\
\hline Housewife & 293 & 147 (29.9) & $146(29.7)$ & \\
\hline Others & 24 & $8(1.6)$ & $16(3.2)$ & \\
\hline \multicolumn{5}{|l|}{ SES } \\
\hline Poor & 318 & $176(37.5)$ & $142(29.4)$ & 0.001 \\
\hline Middle & 319 & $163(34.7)$ & $156(32.2)$ & \\
\hline Wealthier & 316 & $130(27.8)$ & $186(38.4)$ & \\
\hline
\end{tabular}

more likely to come from households with three or more children $(p<0.001)$, and those with 6 or more people $(p=0.001)$ compared to controls. Children with injuries were more likely to be left alone at home as compared to controls $(\mathrm{p}=0.001)$, and more children with injuries as compared to controls were left with minor caretakers, $\mathrm{p}=0.001$.

\section{Pattern of Injuries}


Table 2: Comparisons of socio-demographic characteristics of children among the cases and controls

\begin{tabular}{llllll}
\hline Variable & Category & Total & $\begin{array}{l}\text { Cases } \\
\mathbf{n}(\%)\end{array}$ & $\begin{array}{l}\text { Control } \\
\mathbf{n}(\%)\end{array}$ & P value \\
\hline Age (yrs) & $<1$ & 35 & $16(3.2)$ & $19(3.8)$ & 0.9 \\
& $1-4$ & 601 & $301(61.2)$ & $300(61.0)$ & \\
& $5-9$ & 223 & $114(23.2)$ & $109(22.2)$ & \\
& $10-17$ & 125 & $61(12.4)$ & $64(13.0)$ & \\
Sex & Total & 984 & 492 & 492 & \\
& Male & 568 & $285(57.9)$ & $283(57.5)$ & 0.9 \\
No of children & Female & 416 & $207(42.1)$ & $209(42.5)$ & \\
in the house & Total & 984 & 492 & 492 & \\
& $1-2$ & 675 & $304(62.0)$ & $371(76.0)$ & $<0.001$ \\
Number of & $3+$ & 306 & $186(38.0)$ & $120(24.0)$ & \\
People in house & Total & 981 & 490 & 491 & \\
& $3-5$ & 679 & $307(62.4)$ & $372(75.6)$ & 0.001 \\
Child left home & 6+ & 305 & $185(37.6)$ & $120(24.4)$ & \\
Alone & Total & 984 & 492 & 492 & \\
& Yes & 311 & $192(39.6)$ & $119(24.2)$ & 0.001 \\
Child left with & No & 665 & $293(60.4)$ & $372(75.8)$ & \\
a minor caretaker & Yes & 976 & 485 & 491 & \\
& No & 453 & $270(55.7)$ & $183(37.2)$ & 0.001 \\
\hline
\end{tabular}

Injuries noted in this study included fall (32.1\%), burns body, two female children ( $0.4 \%)$ were sexually assault(25.8\%), RTI (13.6\%) and cuts (10.4\%). Seventeen chil- ed (raped) and six children (1.2\%) had drowned. (Figdren $(3.5 \%)$ reported to have been assaulted mostly ure 1$)$.

by peers. Seven $(2 \%)$ children had swallowed a foreign Majority of falls occurred at home (81\%) affecting

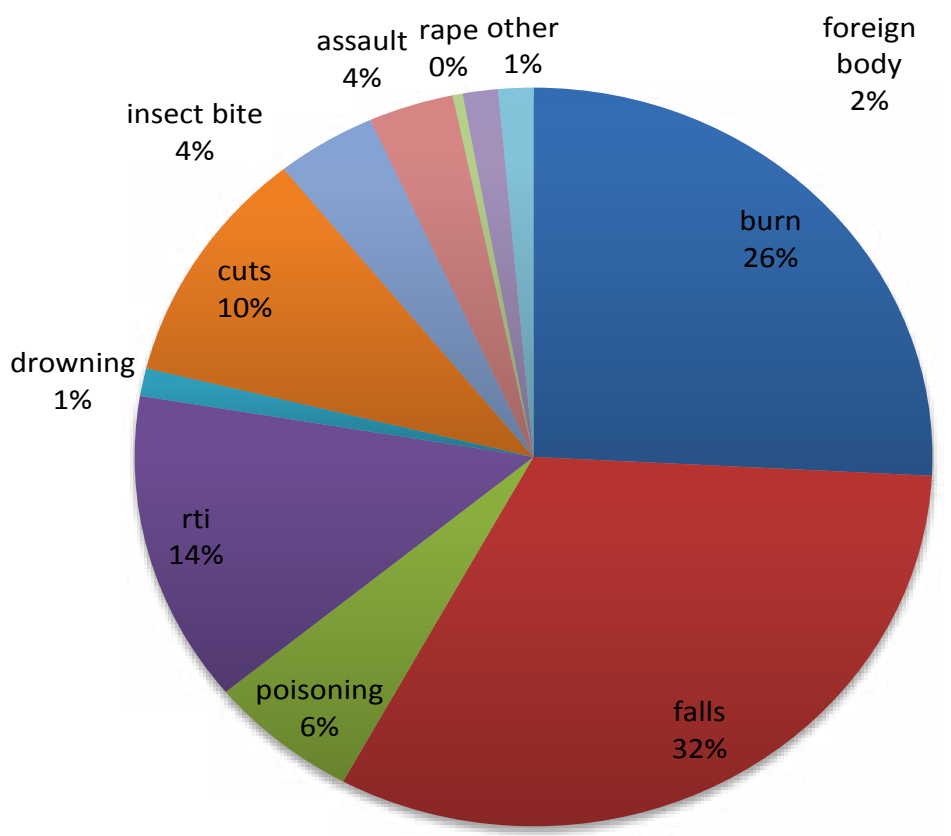

Figure 1: Pattern of injuries among cases

mostly children aged $1-4$ years $(68.4 \%)$. Burns occurred predominantly at home $(98.4 \%)$ and were caused by hot foods $(44.1 \%)$ and water (40.9\%). Majority $(80.7 \%)$ of children who sustained road traffic injuries were pedestrians, and these injuries resulted mainly from motorcycles (53.7\%) and cars (38.8\%). Kerosene (46.7\%) and medicines $(43.3 \%)$ were the predominant types of poisons reported.

Figure 2 describes type of injury according to sex of children; more male children were injured (58\%) as compared to female children $(42 \%)$. Most injuries in 
this study $(70.0 \%)$ were reported to have occurred at home while $7.1 \%$ and $9.4 \%$ occurred at school and sport areas/venues, respectively.

\section{Risk Factors for Childhood Injuries}

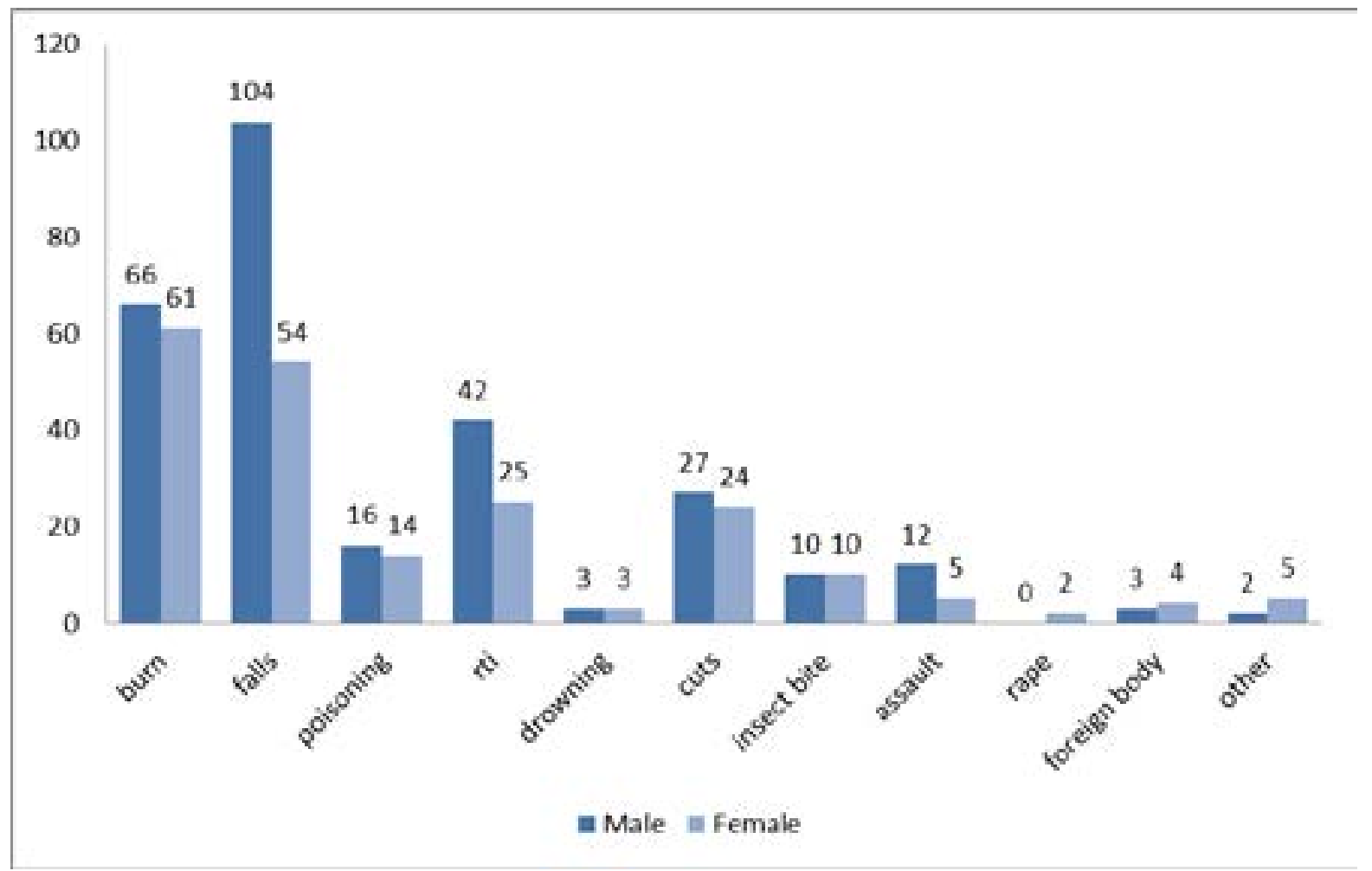

Figure 2: Number of male and female cases recruited

Child related independent risk factors for injuries are living child unsupervised at home and increased number of children and adults in the household as described in Table 3. Children left at home alone were about two times more likely to be injured as compared to those with proper supervision after adjusting for confounders $(\mathrm{AOR}=1.6,95 \% \mathrm{CI}(1.1 ; 2.4)$. Similarly, children left with minor caretakers had 1.5 fold increased odds of in- jury $(\mathrm{AOR}=1.6,95 \% \mathrm{CI}: 11-2.3)$.

Living in households with three or more children had 1.7 times increased probability of injury compared to those with 1-3 children (AOR $=1.3,95 \%$ CI:1.0 - 1.9) \}. Moreover, households with more than 6 individuals had almost twice the likelihood of childhood injury as compared to those households with less than 6 people $\{\mathrm{AOR}=1.7,95 \% \mathrm{CI}: 1.3-2.3)$.

Maternal age and socio-economic status, number of 
Table 3: Logistic regression of all independent risk factors for injuries among children aged less than 18 years in Dar es Salaam

\begin{tabular}{|c|c|c|c|c|}
\hline Variable & Category & $\begin{array}{l}\text { OR } \\
\text { CI })\end{array}$ & $\begin{array}{l}* \text { AOR } \quad(95 \% \\
\text { CI) }\end{array}$ & ${ }^{x} \mathbf{p}$ - value \\
\hline \multirow{4}{*}{$\begin{array}{l}\text { Child } \\
\text { age (years) }\end{array}$} & $<1$ & 1 & 1 & \\
\hline & $1-4$ & $1.2(0.6-2.3)$ & $1.2(0.5-2.9)$ & 0.67 \\
\hline & $5-9$ & $1.2(0.6-2.5)$ & $1.1(0.7-1.9)$ & 0.54 \\
\hline & $10-17$ & $1.1(0.5-2.4)$ & $1.0(0.5-1.6)$ & 0.9 \\
\hline \multirow[t]{2}{*}{ Sex } & Male & 1 & 1 & \\
\hline & Female & $1.0(0.8-1.3)$ & $1.0(0.8-1.3)$ & 0.99 \\
\hline \multirow{4}{*}{$\begin{array}{l}\text { Child left } \\
\text { alone } \\
\text { Child } \\
\text { with a minor } \\
\text { caretaker }\end{array}$} & No & 1 & 1 & \\
\hline & Yes & $2.0(1.5-2.7)$ & $1.6(1.1-2.3)$ & 0.02 \\
\hline & No & 1 & 1 & \\
\hline & Yes & $2.1(1.6-2.7)$ & $1.5(1.1-2.2)$ & 0.010 \\
\hline \multirow{2}{*}{$\begin{array}{l}\text { Number of } \\
\text { children in } \\
\text { the household }\end{array}$} & $1-2$ & 1 & 1 & \\
\hline & $3+$ & $1.7(1.3-2.2)$ & $1.4(1.0-2.0)$ & 0.032 \\
\hline $\begin{array}{l}\text { Number of } \\
\text { people in the } \\
\text { household }\end{array}$ & $\begin{array}{l}3-5 \\
6+\end{array}$ & $\begin{array}{l}1 \\
1.8(1.4-2.4)\end{array}$ & $\begin{array}{l}1 \\
1.8(1.3-2.6)\end{array}$ & 0.001 \\
\hline \multirow[t]{3}{*}{ Maternal age } & $35+$ & 1 & 1 & \\
\hline & $15-24$ & $1.4(0.9-2.0)$ & $2.2(1.4-3.6)$ & 0.001 \\
\hline & $25-34$ & $1.6(1.2-2.2)$ & $2.0(1.4-2.9)$ & $<0.001$ \\
\hline \multirow[t]{5}{*}{ Occupation } & Peasant & 1 & 1 & \\
\hline & Employed & $0.5(0.2-1.0)$ & $0.9(0.4-2.0)$ & 0.91 \\
\hline & Petty & $0.4(0.2-0.8)$ & $0.6(0.3-1.2)$ & 0.18 \\
\hline & trader & $0.5(0.2-0.9)$ & $0.6(0.3-1.2)$ & 0.22 \\
\hline & Housewife & & & \\
\hline \multirow[t]{3}{*}{ Marital status } & Single & 1 & 1 & \\
\hline & Married & $1.3(0.9-1.8)$ & $1.3(0.9-1.9)$ & 0.20 \\
\hline & Separated & $1.0(0.6-1.7)$ & $1.0(0.6-1.8)$ & 0.93 \\
\hline \multirow{3}{*}{$\begin{array}{l}\text { Economic } \\
\text { status }\end{array}$} & Wealthier & 1 & 1 & \\
\hline & Middle & $1.5(1.1-2.0)$ & $1.6(1.1-2.4)$ & 0.011 \\
\hline & Poor & $1.7(1.3-2.4)$ & $1.5(1.0-2.1)$ & 0.036 \\
\hline
\end{tabular}

OR-Odds ratio; AOR- Adjusted odds ratio; CI- Confidence Interval, ${ }^{\star} \mathrm{p}$-value for adjusted odds ratio *All variables are adjusted for others in the table

people in the household and leaving children alone or under supervision of minors were noted to be independent predictors of childhood injuries as described in Table 3. Young mothers had 2 fold increased risk of childhood injuries as compared to older mothers. Households with poor and middle socio-economic level had about 1.5 fold increased likelihood of childhood injury as compared to wealthier ones.

\section{Discussion}

This case control study was carried out to determine pattern and risk factors for childhood injuries in Dar es Salaam, Tanzania. Falls, burns, RTIs and cuts were the main types of injury reported. Overall, cases were more likely to be males than females in this population. Risk factors for injuries noted in this study included poor children supervision, overcrowding, having more than 3 children in the house, lower economic status and low maternal age.

Male children were predominantly injured in this study; this is consistent with other reports and is usually attributed to higher level of activities as compared to female children. ${ }^{15,16}$ Younger children (1-4 years) are usually very curious in exploring their immediate environment thereby exposing themselves to hazards, were more involved in injuries in this study. ${ }^{17}$

Common childhood injuries reported indel from 
sub-Saharan Africa were also noted in this study, which include falls, burn, RTI, poisoning and drowning. ${ }^{18-22}$ Majority of injuries was sustained at home like reports from previous studies, raising serious concerns as homes are expected to be safe. ${ }^{16,17}$ There is a need increase advocacy and promote strategies for making homes safe.

Younger children were predominantly injured through falls, although majority of falls result in mild injuries, they have potential for causing serious morbidities including brain injuries contributing to mortality. ${ }^{16,23}$ Scalding was also commonly reported among younger children (below 2 years), these occurred at home and could have happened in the presence of adults, as has been the case from other studies. ${ }^{916}$ Burn injuries result in serious deformity and contribute to high mortality among children. ${ }^{24}$ Observed findings in this study calls for effort to advocate for anticipatory guidance and supervision of young children to prevent injuries from fire and hot liquids/foods.

The surge of motor traffic injuries in many urbanized African regions is attributed to changes in public transportation following introduction of motorcycles, in this study motorcycle related RTI were common among pre-school and school children. This finding, which is similar to other findings from the region, underscores the need for improved infrastructure and enforcement of traffic laws in Tanzania. ${ }^{8,25}$

Poisoning involving medicines and household items like kerosene is affect young children, in this study poisoning was also reported contributing to injury consistent with other reports from other studies in the region. 6,26 , ${ }^{27}$. Therefore there is a need to keep emphasis of storing medicine and hazardous household items out of children's reach.

Childhood injuries are common in low- and middle-income countries and are influenced by several factors including family income, maternal education, family structure and issues related to accommodation. ${ }^{21,29} \mathrm{Im}$ proved quality of life and parenting education are important especially at community level. Proper planning in big cities like Dar es Salaam, which are rapidly growing and over-populated, should be considered to make them safe cities for children. ${ }^{11}$

Children supervision in homes plays an important role in prevention of childhood injuries, therefore efforts for promoting improved childhood supervision and safe household environment should be emphasized.. ${ }^{16}$ Similarly the habit of leaving older children to supervise younger ones should be strongly discouraged.

This study was conducted in the hospital setting, therefore recruited participants are those with moderate to severe injuries, minor injuries which are the most common occurring in the community might not be presented to health facilities, therefore the findings of this study may not be generalizable to the community setting. Another important limitation of this study was not grading injuries and following up of injured participants to determine what treatment was offered and their outcomes making it difficult to ascertain the consequence of injuries.

\section{Conclusion}

Falls, burns and road traffic accidents were the predominant injuries. Injuries were more common among unsupervised children and those from poor and overcrowded households. There is a need for initiating community campaigns to raise awareness on childhood injuries focusing on making home environment safe and improving supervision for children.

\section{Competing interests}

The authors declare that they have no competing interests

\section{Author's contribution}

RM designed the study, collected data, analyzed and wrote initial report for this study. FFF participated in study design and prepared the manuscript for this article. EM and AM provided critical comments and advise in study design and analysis. All authors read and approved this manuscript.

\section{References}

1. GBD 2017 Causes of Death Collaborators. Global, regional, and national age-sex-specific mortality for 282 causes of death in 195 countries and territories, 1980-2017: a systematic analysis for the Global Burden of Disease Study 2017. The Lancet. 8 Nov 2018;392:1736-88. doi: http://dx.doi.org/10.1016/ S0140-6736(18)32203-7.

2. Adeloye D, Bowman K, Chan KY, Patel S, Campbell 
H, Rudan I: Global and regional child deaths due to injury: assessment of evidence. J Glob Health 2018, 8 (2) 3. Ramirez SS, Hyder AA, Herbert HK, Stevens K: Unintentional injuries: magnitude, prevention and control. Annu Rev Public Health 2012.33:175-191

4. Krug EG, Sharma GK, Lozano R. The global burden of injuries. Am J Public Health 2000; 90:523-6 PubMed. 5. Alonge O, Hyder AA: Reducing the global burden of childhood unintentional injuries. Arch Dis Child 2014; 99: 62-69. doi:10.1136/archdischild-2013-304177

6. Hyder AA, Sugerman DE, Puvanachandra P, Razzak J, El-Sayed H, Andres Isaza A, Rahman F, Peden M: Global childhood unintentional injury surveillance in four cities in developing countries: a pilot study. Bull World Health Organ 2009; 87: 345-352

7. Gallaher JR, Wildfire B, Mabedi C, Cairns B.A., Charles AG: Intentional injury against children in Sub-Saharan Africa: A tertiary trauma Centre experience. Injury 2016 Apr; 47 (4): 837- 41

8. Simon R, Gilyoma JM, Dass RM, Mchembe MD, Chalya PL: Paediatric injuries Bugando Medical Centre in Northwestern Tanzania: a prospective review of 150 cases. Journal of Trauma Management \& Outcomes 2013 $7: 10$.

9. Chalya PL, Mabula JB, Dass RM, Giiti G, Chandika AB, Kanumba ES, Gilyoma JM: Pattern of childhood burn injuries and their management outcome at Bugando Medical Centre in Northwestern Tanzania. BMC Research Notes 2011, 4:485

10. Dal Santo JA, Goodman RM, Glik D, Jackson K: Childhood Unintentional Injuries: Factors Predicting Injury Risk Among Preschoolers. J Pediatr Psychol 2004; 29(4): 273-283

11. Gracey M: Child health in an urbanizing world. Acta Paediatr 2002, 91:1-8.

12. Tanzania population and hosing census 2012

13. Werneck GL, Reichenheim ME: Paediatric burns and associated risk factors in Rio de Janeiro, Brazil. Burns 1997;23(6):478-83

14. Kasiulevičius V, Šapoka V, Filipavičiūtè R: Sample size calculation in epidemiological studies. Gerontologija 2006; 7(4): 225-231

15. Li Q, Alonge O, Lawhorn C, Ambaw Y, Kumar S, Jacobs T, et al.: Child injuries in Ethiopia: A review of the current situation with projections. PLoS One 2018; 13(3): e0194692.https:// doi.org/10.1371/journal. pone.0194692

16. Tiruneh BT, Bifftu BB, Anlay DZ, Yismaw YS, Tesfaye E, Dachew BA: Factors associated with unintentional injury among the paediatric age population in the hospitals of Amhara National Regional State, Ethiopia. Afr J Emerg Med 2017; 7: S55-S59

17. Abdur-Rahman LO, Taiwo JO, Ofoegbu CKP, Adekanye AO, Ajide OO, Ijagbemi CY, Solagberu BA: Community survey of childhood injuries in North-Central Nigeria. Annals of Pediatric Surgery 2015; 11(2): 136-9 18. Esin IA, Alabi S, Lawal OA: Childhood injuries in a tertiary institution in north east Nigeria. Afr J Paediatr Surg 2013; 10:367-70

19. Jonkheijm A, Zuidgeest JH, van Dijk M, van As ÀB: Childhood unintentional injuries: Supervision and first aid provided. Afr J Paediatr Surg 2013; 10:339-44

20. Gad A, AL-Eid R, Al-Ansary S, Saeed A, Kabbash A: Pattern of Injuries among Children and Adolescents in Riyadh, Saudi Arabia: a household survey. J Trop Pediat 2011; 57 (3): 179-184

21. Sharma SL, Reddy NS, Ramanujam K, Jennifer MS, Gunasekaran A, Rose A, John SM, Bose A, Mohan VR: Unintentional injuries among children aged $1-5$ years: understanding the burden, risk factors and severity in urban slums of southern India. Injury Epidemiology 2018; $5: 41$

22. Hulme P: Mechanisms of paediatric trauma at a rural hospital in Uganda. Rural and Remote Health 2010; 10: 1376. Available: www.rrh.org.au/journal/article/1376

23. Bulut M, Koksal O, Korkmaz A, Turan M, Ozguc $\mathrm{H}$ : Childhood falls: characteristics, outcome, and comparison of the Injury Severity Score and New Injury Severity Score. Emerg Med J. 2006; 23(7): 540-545.

24. Outwater AH, Ismail $H$, Mgalilwa L, Temu MJ, Mbembati NA: Burns in Tanzania: morbidity and mortality, causes and risk factors: a review. Int J Burn Trauma 2013;3(1):18-29

25. Staton C, Vissoci J, Gong E, Toomey N, Wafula R, Abdelgadir J, et al: Road Traffic Injury Prevention Initiatives: A Systematic Review and Meta-summary of Effectiveness in Low and Middle-Income Countries. PLoS One 2016; 11(1): e0144971

26. Ansong D, Nkyi C, Appiah CO, Amuzu EX, Frimpong CA, Nyanor I, Nguah SB, Sylverken J: Epidemiology of paediatric poisoning reporting to a tertiary hospital in Ghana. SAJCH 2016; 10 (1): 68-70

27. Mbarouk GS, Sawe HR, Mfinanga JA, Stein J, Levin S, Mwafongo V, Runyon MS, Reynolds TA, Olson KR: Patients with acute poisoning presenting to an urban emergency department of a tertiary hospital in Tanzania. BMC Res Notes 2017; 10:482 PubMed DOI 10.1186/s13104-017-2807-2

28. Boyle KL, Periyanayagam U, Babu KM, Rice BT, Bisanzo M: Pediatric Poisonings in a Rural Ugandan 
Emergency Department. Pediatr Emerg Care 2017. doi: Palestine: Findings from the National Study of Pales10.1097/PEC.0000000000001265 tinian Schoolchildren. International Journal of Population

29. Jildeh C, Abdeen Z, Al Sabbah H, Philalithis A: Research, vol. 2013, Article ID 629159, 7 pages, 2013. Unintentional Injuries among School-Aged Children in https://doi.org/10.1155/2013/629159. 